\title{
Research Paper \\ Prediction of objective and subjective career success by career anchors among lawyers and jurists
}

Fatemeh Samiee $^{1}$

1. Assistant Professor, Department of Counseling, Faculty of Education \& Psychology, University of Isfahan, Isfahan, Iran.

Citation: Samiee F. Prediction of objective and subjective career success by career anchors among lawyers and jurists. J of Psychological Science. 2022; 20(107): 1979-1992.

URL: https://psychologicalscience.ir/article-1-1028-fa.html
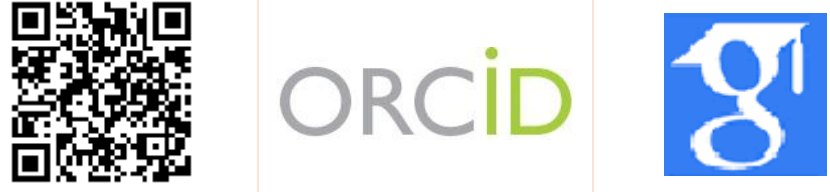

$\underline{10.52547 / J P S .20 .107 .1979}$
A R T I C L E I N F O

\section{A B S T R A C T}

\begin{tabular}{l}
\hline Keywords: \\
Career success, \\
Career anchors, \\
Lawyers, \\
Jurists
\end{tabular}

Received: 17 Nov 2020 Accepted: 03 Jan 2021 Available: 21 Jan 2022
Background: Various research has been done about job success in different strata of society. But, there is little research that has examined the career success of lawyers and jurists.

Aims: The study aimed to predict career success (subjective and objective) through career anchors among lawyers and jurists in Isfahan in the year 2019.

Methods: A descriptive-correlational design was utilized to study. Thus, 152 lawyers (65 females and 87 male) were selected through convenience sampling and answered to the study instruments that consisted of Career Success Questionnaire (Samiee et al., 2014) and Career Anchors Questionnaire (Schien, 1985). The data were analyzed using Pearson's correlation and multiple regression analysis.

Results: The results of descriptive statistics showed that the highest career anchor was technical and functional competencies, and then, service and lifestyle related to work-family balance among lawyers and Jurists. Besides, the prevalence of subjective career success was more than objective career success. Also, technical and functional competencies, independence and service predicted of subjective career success $(\mathrm{p}<0.05)$. Moreover, technical and functional competencies and challenge predicted objective career success $(\mathrm{p}<0.05)$, which explained 20 and 15 per cent of the variances of subjective career success and objective career success.

Conclusion: Based on the results of this study it can be concluded that the subjective and objective career success could be increased by increasing competencies, independence and challenging cases among lawyers and jurists.

* Corresponding Author: Fatemeh Samiee, Assistant Professor, Department of Counseling, Faculty of Education \& Psychology, University of Isfahan, Isfahan, Iran.

E-mail: f.samiee@edu.ui.ac.ir

Tel: (+98) 3137935413

2476-5740/ (C) 2021 The Authors. This is an open access article under the CC BY-NC-ND license

(https://creativecommons.org/licenses/by-nc/4.0/). 


\section{Extended Abstract}

\section{Introduction}

Introduced by van Manen and Schein in the 1970s, the concept of career success measures one's perception and evaluation of their career performance and has two dimensions: objective and subjective. Many researchers assume the objective dimension to be more important than the subjective one since the former involves external variables of a job, such as salary, security, vacation, promotion, and organizational position change. These are determined by society and represent a prerequisite of career success. The subjective dimension, refers to one's perception of experiences such as progress, demand and value realization, perceived security, and freedom achieved in the career. These experiences or internal criteria can influence career adaptability, compatibility, and development. The objective (external) and subjective (internal) dimensions of career success play a key role in mental health and quality of work life in all careers, particularly lawyers.

Anchors are internal components of a career. They arise from the personal life experiences of an individual and help concentrate their energy on a certain objective. Hence, they enhance motivation to fulfill career activities and provide wide resources and career dynamics, leading to career success. Anchors are the frontline of making decisions that create mobility, dynamism, activity, and career. Thus, the career future of an individual may be predicted based on their career anchor size and type. Schein (1996) proposed eight career anchors, including (1) independence, which enables individuals to fulfill tasks in their way, (2) job security, which refers to the confidence that an individual will stay at the same geographical position to fulfill their tasks, (3) technical/functional competencies, in which knowledge, skills, and experience are the most important factors, (4) general management competencies (individuals with general management competencies promote to higher positions, can observe the behavior and efforts of others, and establish coordination and organization, (5) entrepreneurial creativity, in which businesses are launched proportionately to creativeness, (6) service and dedicated (serving and dedicated individuals are willing to work for others under their value system to improve others' lives, (7) pure challenge, where there are pleasurable efforts to handle crises and overcome problems, and (8) lifestyle based on the work-family balance (those with this career anchor seek to bring a balance between their career, personal, and family concerns and have flexibility and individual growth. Schein (1996) believed that career anchors could influence selection, decision-making, and objective and subjective career success. Since lawyers have rarely been investigated in psychological and consulting studies on career success and career anchors, the present study seeks to realize whether the career anchor type could predict the objective and subjective career success of lawyers.

\section{Method}

The present work adopted a correlational methodology. The statistical population consisted of lawyers in Isfahan, Iran. The career success questionnaire of Samiee et al. (2014) was employed to collect data. It involves twelve items and measures career success in the objective and subjective dimensions. Items 1-6 measure salary satisfaction, organizational promotion, and received benefits (i.e., objective career success), while Items 7-12 evaluate progress, security, growth, freedom, and balance (subjective career success). Cronbach's alpha was used to evaluate the reliability of the questionnaire. The reliability was calculated to be 0.70 for objective career success and 0.72 for subjective career success. Schein's (1996) career anchor questionnaire was also utilized. It consisted of 40 items measuring career anchors. Its sub-measures include technical/functional (Items 1-5), general management (6-10), independence (11-15), entrepreneurial creativity (16-20), job security (21-25), service and dedication (26-30), pure challenge (31-35), and lifestyle under the work-family balance (36-40). Cronbach's alpha was utilized to evaluate the reliability of Schein's questionnaire. The overall reliability was obtained to be 0.8 for the questionnaire. Also, the alpha was measured to be $0.36,0.61,0.56,0.71,0.64,0.73,0.78$, and 0.66 for technical/functional competencies, general 
management, entrepreneurial creativity, independence, job security, pure challenge, service/dedication, and lifestyle, respectively. The data were analyzed using the Pearson Correlation Coefficient and Multiple Regression (stepwise) in SPSS-23.

\section{Results}

The findings revealed significant relationships of technical/functional competencies, service/dedication, and pure challenge with objective career success $(\mathrm{p}<0.001)$. All the career anchors, except for general management and job security, were found to be significantly related to subjective career success $(p<0.001)$. Moreover, based on $\Delta R^{2}$, it can be said that technical/functional competencies explained $11 \%$ of the objective career success variance $(\mathrm{F}=19.34, \mathrm{p}<0.001)$, while the pure challenge anchor had only a $4 \%$ contribution to the prediction. In other words, the combination of technical/functional competencies and pure challenge explained $15 \%$ of the objective career success variance $(\mathrm{F}=13.62$, $\mathrm{p}<0.001)$. According to $\Delta \mathrm{R}^{2}$, it can be said that technical/functional competencies explained $14 \%$ of the subjective career success variance $(F=24.72$, $\mathrm{p}<0.001)$, and the independence anchor improved the prediction by only $4 \%$. The addition of the service/dedication anchor to the model led to a $2 \%$ improvement in the predictive power. Thus, the combination of technical/functional competencies and independence explained $18 \%$ of the subjective career success variance $(\mathrm{F}=17.06, \mathrm{p}<0.001)$, while the combination of independence, technical/functional competencies, and service/dedication explained $20 \%$ of the subjective career success variance $(\mathrm{F}=12.94$, $\mathrm{p}<0.001)$. Furthermore, it can be said that technical/functional competencies $(\beta=0.22, t=2.58)$ had a greater effect than independence $(\beta=0.19$, $t=2.54)$ and service/dedication $(\beta=0.17, t=2.00)$ on the subjective career success prediction of lawyers.

\section{Conclusion}

The present study aimed to predict the subjective and objective career success of layers based on career anchors. The findings indicated that technical/functional competencies and pure challenge, among other career anchors, had the greatest effects on the prediction of objective career success, whereas technical/functional competencies, independence, and service/dedication had the largest contributions to the prediction of subjective career success. Therefore, technical/functional competencies predicted both objective and subjective career success. Technical/functional competencies are a talent-based anchor. Those who have the technical/functional competency anchor seek to develop their talents, achieve lifelong learning, and enhance their knowledge and skills since survival in today's ever-changing world is dependent on enhancing legal knowledge and professional skills. Also, lawyers are offered more challenging cases when they improve in professional knowledge, skill, and experience, obtaining a higher position in their job. This results in objective success (i.e., income, promotion, and benefits) and, consequently, job satisfaction and subjective success. Moreover, legal practice is a complicated job with high social responsibility in complicated, stressful situations. Lawyers chose their job to achieve high-level professional objectives and seek to demonstrate their technical and functional competencies in daily life since they realize that their expertise and skills could push them toward professional growth. Also, the job, communication, commitment, received support, and related activities can induce a sense of pleasure and competence.

It was also found that pure challenge contributed to the prediction of objective career success. In this respect, it can be said that it is essential to deal with career challenges, apart from specialized knowledge and technical/functional competencies, in legal practice. Pure challenge is a value-based anchor. Value-based career anchors are related to occupational and organizational identity. Those who can meet their occupational or organizational demands through their values receive incentives from the organization. These incentives may be in a financial form. In other words, legal practice is a challenging job. A lawyer understands the nature and social dimensions of their job and the associated challenges. They pursue their goals, interests, and demands, and this creates personal motives for professional growth. Therefore, challenges are 
believed to be a sign of career success and increase in number in the future.

As pure challenge was found to be the second-largest predictor of objective career success, independence was derived to be the second-largest predictor of subjective career success. In this respect, it can be said that independence is a demand-based anchor. Independence and judicial immunity are basic requirements of legal practice and are mentioned in legal documents. Independent lawyers have higher satisfaction with adhering to morals, realizing professional growth, and achieving professional objectives and a good feeling for fulfilling their job. Internal satisfaction is subjective career success. Service and dedication were found to be the thirdlargest predictor of subjective career success. Working for others to improve their lives becomes important based on the values of society in the service/dedication anchor. Professional and dynamic motives appear among layers based on a complicated set of interests, demands, values, the desire for justice, the love of the truth, patriotism, and idealism. These motives are strongly influenced by subjective factors. Legal practice is a purposeful profession. This can manifest in the tendency to serve, establish social justice, and support the rights and interests of citizens. Thus, subjective career success can be affected by the extent to which service and dedication are realized in a lawyer. As a result, it can be concluded that talent, value, and demand are important in the career success prediction of lawyers. In other words, legal practice is a multi-dimensional profession and can develop talents and values and meet demands.

\section{Ethical Considerations}

Compliance with ethical guidelines: In this study, one of the ethical considerations was that the participants participated in the research consciously and voluntarily and were free to refuse from this research. Also, they were reminded that the questionnaires were anonymous and data would be analyzed collectively.

Funding: This research has been done without receiving funds. Authors' contribution: In this research, Fatemeh Samiee developed the original idea, abstracted and analyzed data, wrote the manuscript, and is guarantor.

Conflict of interest: This study does not have anything conflict of interest.

Acknowledgments: The author would like to thank all the lawyers and jurists who assisted in this research. 


\section{يّشبينى موفقيت شغلى عينى و فاعلى وكلا و حقوقدانان براساس لنتر كاههاى مسير شغلى}

\section{فاطمه سميعى"}

1. استاديار، كروه مشاوره، دانشكده علومتربيتى و روانشناسى، دانشكاه اصفهان، اصفهان، ايران.

\begin{tabular}{|c|c|}
\hline جكيده & 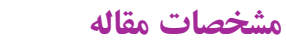 \\
\hline زمينه: مطالعات مختلفى بر موفقيت شغلى در اقشار مختلف جامعه يرداخته است. اما كمتر يزووهشى رامىتوان يافت كه موفقيت شغلى وكلا & 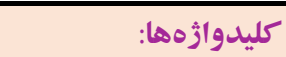 \\
\hline و حقوقدانان را بررسى نموده باشد. & 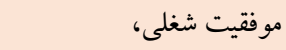 \\
\hline هدف: يُشبينى موفقيت شغلى عينى و فاعلى بر اساس لنكر كاههاى مسير شغلى در و كلاو حقوقدانان شهر اصفهان در سال Ir ا بود. & 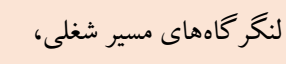 \\
\hline روش: طرح تُزوهش توصيفى از نوع همبستخى بود. به اين منظور، 10 نفر از و كلا و حقوقدانان (9Dزن و AV مرد) به شيوه در دسترس & و كلا، \\
\hline \multirow{2}{*}{\multicolumn{2}{|c|}{ 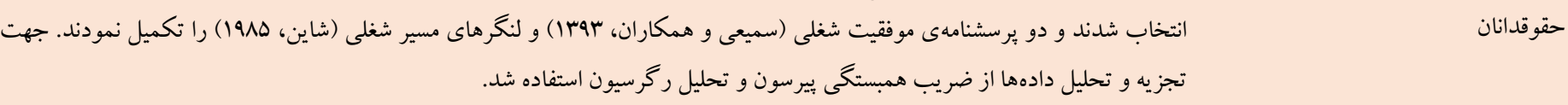 }} \\
\hline & \\
\hline \multicolumn{2}{|l|}{ يافته ها: نتايج حاصل از آمار توصيفى نشان داد شايستخى فنى - كاركردى در بين وكلا و حقوقدانان در رتبه اول، خدمت و فداكارى در } \\
\hline \multicolumn{2}{|l|}{ مر تبه دوم و سبك زندگى با محوريت تعادل كار - خانو اده در رتبه سوم قرار داشت. همجنين، ميانگين موفقيت شغلى فاعلى بالاتر از ميانگين } \\
\hline \multicolumn{2}{|l|}{ موفقيت شغلى عينى بود. علاومبراين، از بين هشت بعد لنكر كاههاى مسير شغلى، سه بعد شايتخى، استقلال و خدمت و فداكارى ييشيينى } \\
\hline \multicolumn{2}{|l|}{ 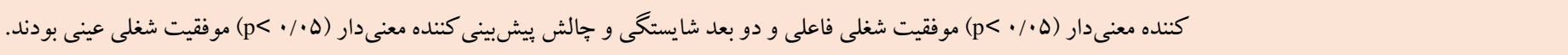 } \\
\hline به طورى كه توانستند ·r و ال درصد از واريانس موفقيت شغلى را تبيين كنند. & 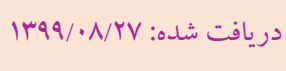 \\
\hline نتيجه كيرى: براساس يافتهاى يُووهش مىتوان جنين نتيجه گيرى نمود كه با افزايش شايستخىها و نيز دادن استقلال بيشتر و ارجاع برونده & 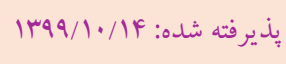 \\
\hline هاى جالشى به و كلا و حقوقدانان مى توان موفقيت شغلى فاعلى و عينى را در آنها افزايش داد. & 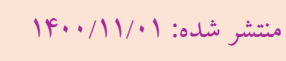 \\
\hline
\end{tabular}

* نويسنده مسئول: فاطمه سميعى، استاديار، گروه مشاوره، دانشكده علوم تربيتى و روانشناسى، دانشكاه اصفهان، اصفهان، ايران. رايانامه: f.samiee@edu.ui.ac.ir

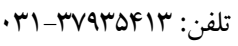


مسير شغلى، برخاسته از تجربيات زندگى شغلى يكك فرد هستند و كمك مقلdمه مى كند تا نيروى فرد يككجا و بر روى يكك هدف ثابت نكه داشته شود. از از اينرو، مى تواند باعث افز ايش انخيزه در انجام فعاليت هاى شغلى (ميرزائيان

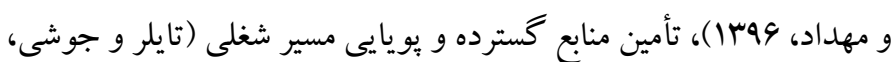

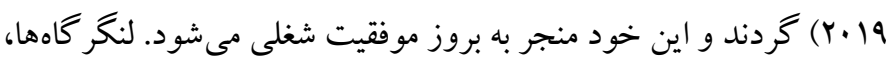

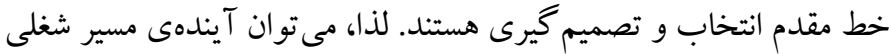
افراد را طبق نوع و ميزان لنكر گاههايشان بيشبينى نمود (شاين، 1999).

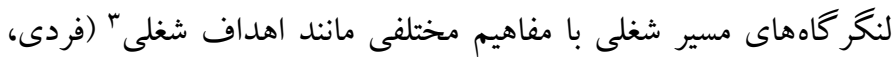

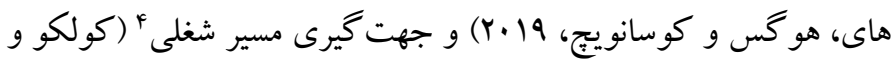

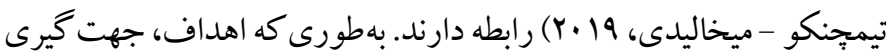

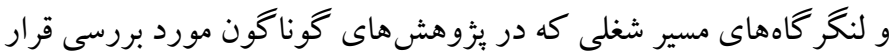
كر فتهاند، جزئى از بعد درونى موفقيت شغلى را تشكيل داده است.

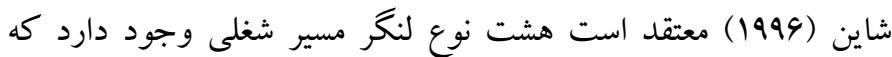
عبارتند از: ا. استقلال كه به افراد اجازه مىدهد كه كارها را به روش خود

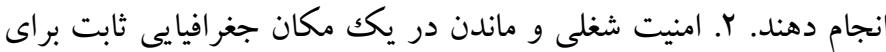
انجام وظايف شغلى است. امنيت شغلى، امنيت مالى را به دنبال دارد.

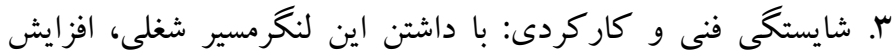

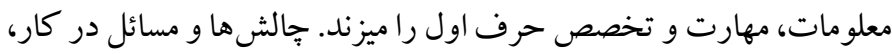
اهميت بيدا مى كند و افراد فنىتر و ماهرتر خواهند شد. f. شايستخى

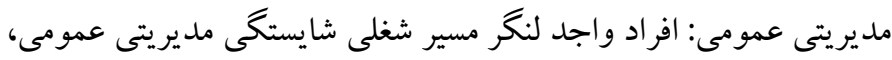

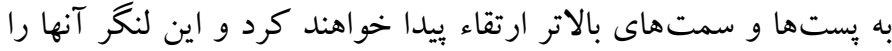

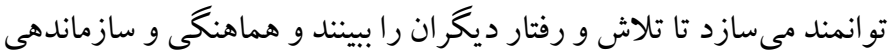

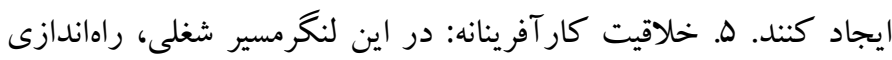
كسب و كار به اندازهاى كه خلاقيت اجازه مىدهد، وجود دارد. كسب و كار كمك مى كند تا قدرت و كنترل بيشترى به دست آيد. معمولا"، افراد واجد اين لنكر مسير شغلى، درآمد بالايى دارند. 9. خدمت و فدرى فداكارى: افر اد خادم و فداكار، بر ایى ديخران كار مى كنند. كارهايى كه مطابق سيستم

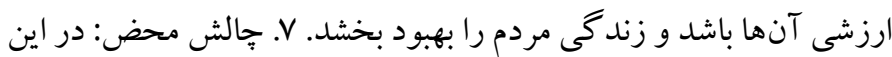
لنكر، تلاش لذتبخش براى حل مسائل و بحرانهاى سخت و و غلبه بر برد مشكلات وجود دارد. افر اد به دنبال مسائل سخت، يُيجِيده و جديد مىروند

${ }^{3}$. career goals

${ }^{4}$. career orientation

1. career success

${ }^{2}$. career anchors 
باشد. در يُزوهشهاى مختلف، لنكر كاههاى شغلى افر ادى كه مانند و كلا، داراى موقعيت هاى شغلى سطح بالا هستند، سنجيده شده است. بطورى كه،

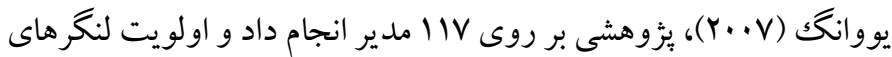

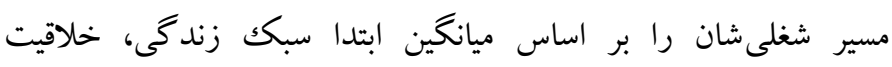

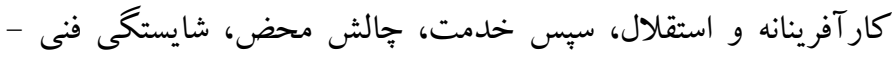

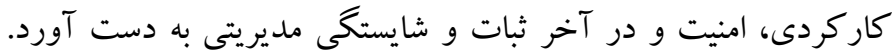
همجنين مطالعه ديخر او، نشان داد كه آرزوى خلاقيت و كار آفرينى اول و آرزوى سبك زندگى در مرتبه آخر است. در بثزوهش سميعى، صادقيان و

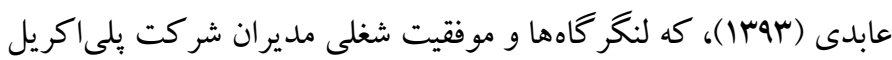

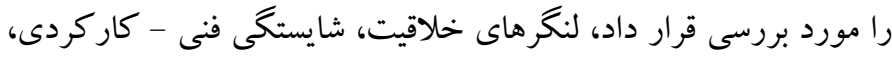
تعادل كار - خانو اده، جالش محض، امنيت، مديريت عمومى و استقلال به ترتيب قرار داشتند. ايخباريا، كاسيه و سيلور (1999) هم نشان دادند كه بين

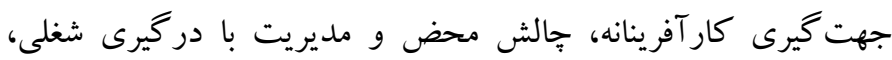

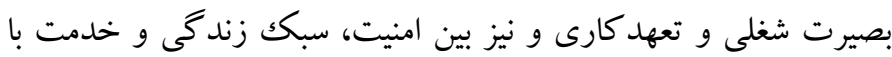
رضايت شغلى ارتباط مثبت وجود دارد. بنابراين، با توجه به مطالعات قبلى و طبق نظر شاين (1999) كه معتقد است لنكر كاههاى مسير شغلى مى تواند در انتخاب و تصميمهاى شغلى تعيين كننده باشد و در نهايت به موفقيت مسير شغلى فاعلى و عينى منجر گردند و نيز با توجه به اينكه و كلا و حقوقدانان جزو گروهى هستند كه كمتر در مطالعات روانشناختى و

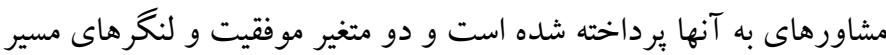
شغلى در اين گروه تاكنون بررسى نشده است، يُوهش حاضر به دنبال باسخ به اين سؤال است كه آيا نوع لنكر مسير شغلى مى تو انند بيشينى بينى كننده

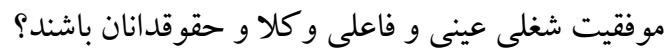

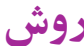

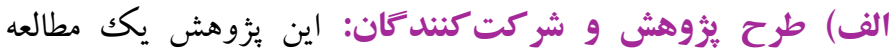
همبستخى بود. جامعه آمارى ثيزوهش، كليه و كلاو حقوقدانان شهر اصفهان بودند كه از ميان آنها به شيوه نمونه گيرى در دسترس، تعداد بها نفر (9D) زن و AV مرد) به عنوان نمونه انتخاب شدند. معيارهاى ورود به بزٔوهش،

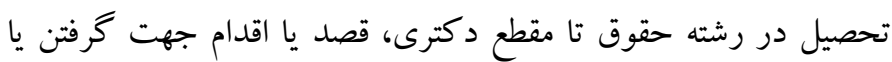
داشتن بروانه وكالت و معيارهاى خروج از يزوهش، ناقص بودن برسشنامه ها و نداشتن مدر كك دكترى بود.
و براى آنها راهحل بيدا مى كنند. \ـ سبك زندگى با محوريت تعادل كار خانو اده: كسانى كه اين لنكر مسير شغلى را داشته باشند؛ به دنبال اين هستند كه بين دغدغههاى شغلى، فردى و خانوادگى خود تعادل برقرار كنند.

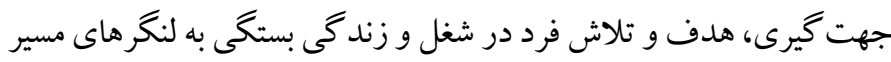
شغلى او دارد. در بُزوهش محمدىمقدم، دهناد، دلاور و علىيور درويشى

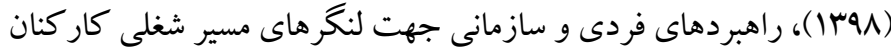

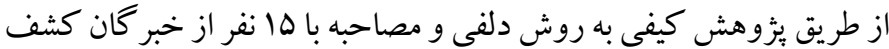
شد. راهبردهاى فردى شامل جانشينيرورى، مديريت استعداد، توانمندى

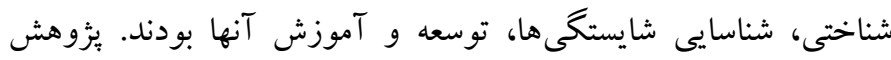

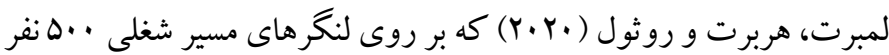
از حسابداران براساس نظريه شاين انجام شد، نشان داد كه در دنياى جديد كارى، لنكرهاى مديريت عمومى، مهارت رهبرى و شبكهسازى جهانى

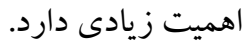
دمجنكو (Y.19)، طى بثزوهش مرورى خود با هدف شناسايى انخيزههاى

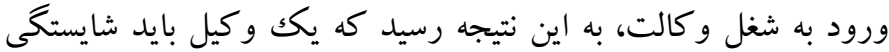
شناختى، هوش هيجانى، توانيى برقرارى ارتباط، كثنكو، مديريت، كسب

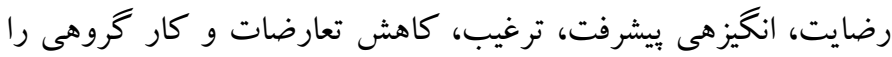

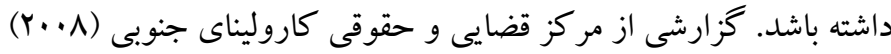

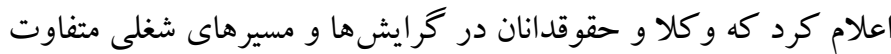

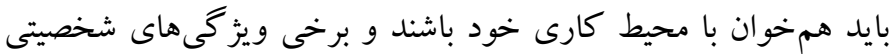
براى افزايش رضايت شغلى آنها لازم است. اين ويز گى ها مى تواند علاوه

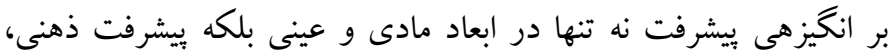

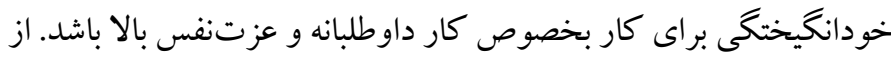

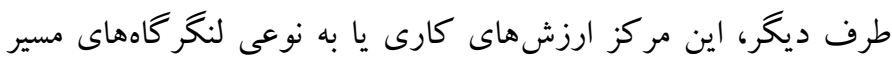
شغلى كه بايد يكك وكيل داشته باشد را اعلام نموده است. ارزشها شامل تعهد كارى، امانت، صداقت، درستى، خلاقيت، عدم قضاوت آنى، توانايى كار كردن با گروههاى مختلف، انعطاف يذيرى، تو انايى كار كردن با منابع

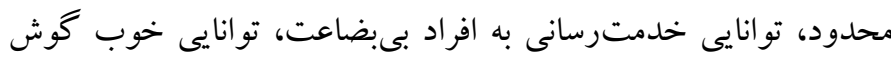

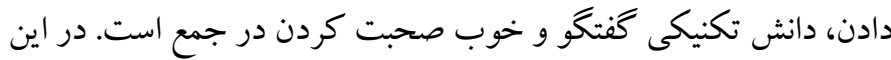

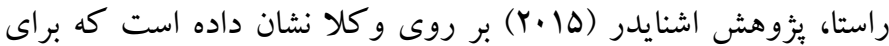
موفقيت در شغل و كالت بايد هفت ويزگى تفكر جندبعدى، توانايى انتقاد، استقلال، سرسختى، نظم، سخت كوشى و ارتباطات خوب وجود داشته 
اين يزوهش، در حيطه شايستكى فنى - كاركردى ضريبى برابر 9V/،، در

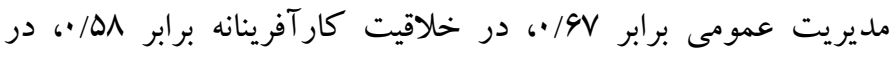

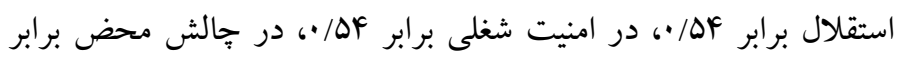

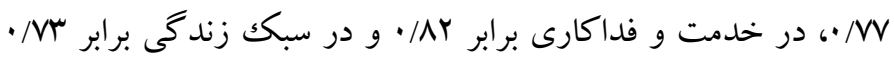
بدست آمد. جهت اجراى بززوهش فوق، محقق و همكاران آموزش ديده او به دفتر و كلاو حقوقدانان مراجعه كردند و يرسشنامه ها را در اختيار آنها

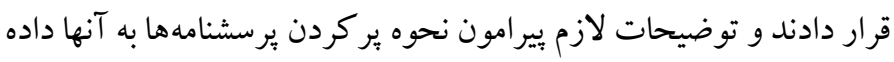

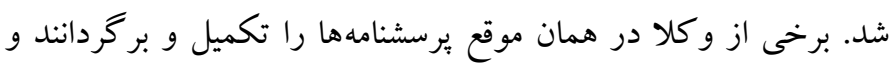

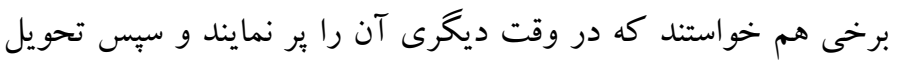

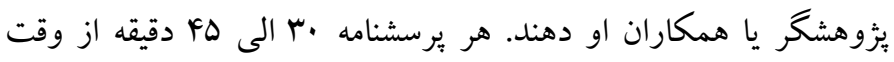
شركت كنند گان را به خود اختصاص داد. دادهها با استفاده از ضريب

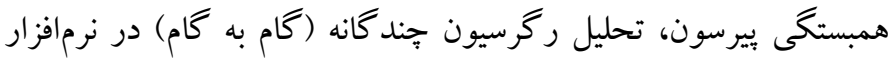

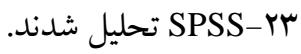

يافته ها

ويزگى هاى جمعيتشناختى گروه نمونه به اين صورت بود كه FV نفر

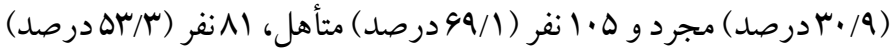

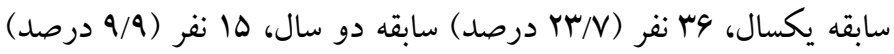
سابقه سه سال، 19 نفر (ه/Y ا درصد) سابقه جهارسال داشتند و يكك نفر هم سابقه خود را اعلام نكرده بود. در واقع ميانخين سابقه وكلا و حقوقدانان انهان

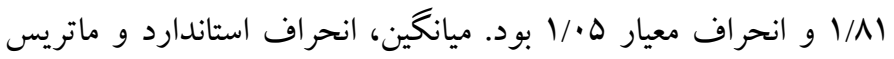

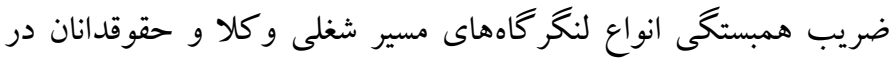
جدول ا آمده است.
ب) (بزار در بثزوه حاضر از برسشنامهاى زير استفاده شد.

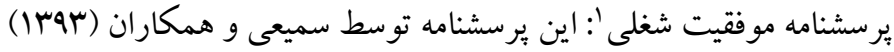
ساخته شد. اين يرسشنامه داراى r ا گويه است و موفقيت مسير شغلى رادر

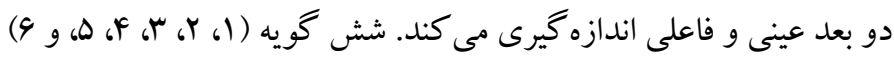
مربوط به رضايت از حقوق، ارتقاء، بـت سازمانى و مزاياى دريافنى و در

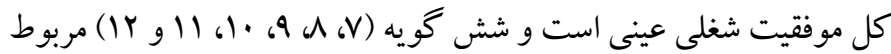
به بيشرفت، امنيت، رشد، آزادى و تعادل و در كل موفقيت شغلى فاعلى

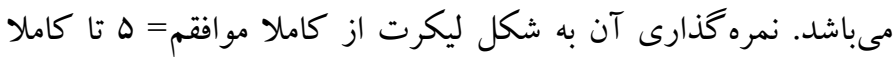

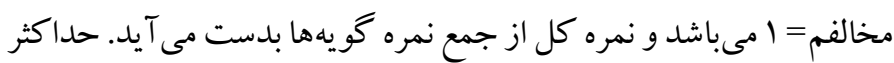

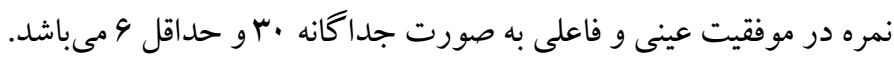

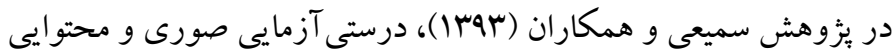
يرسشنامه توسط بِنج متخصص مشاوره شغلى تأييد شد و بر اي قابليت اعتماد

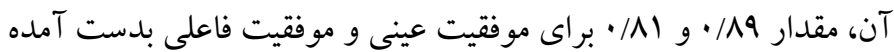

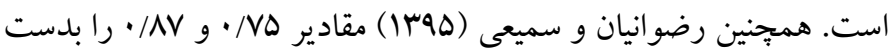

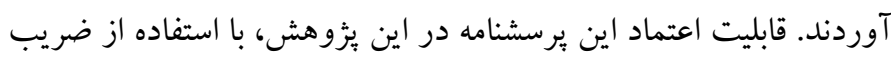

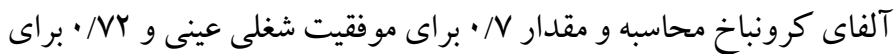
موفقيت شغلى فاعلى بدست آمد.

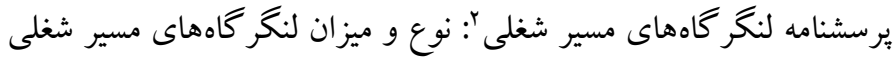

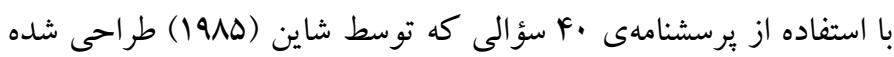

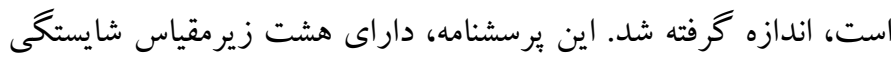

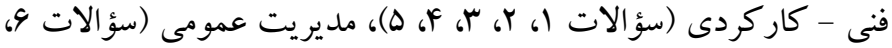

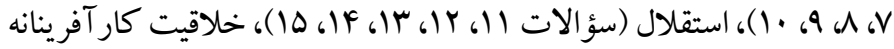

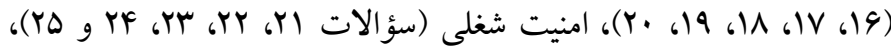

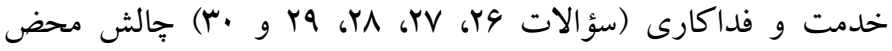

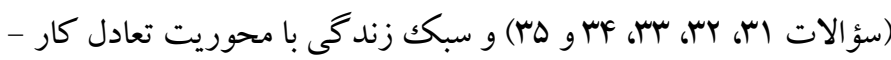

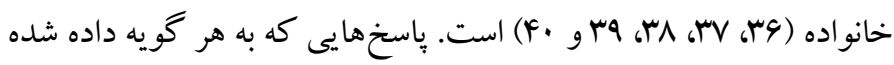

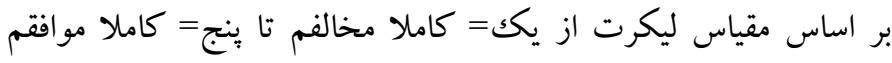

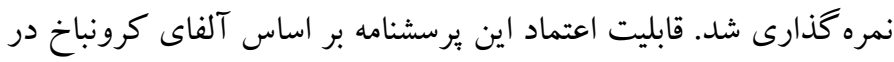

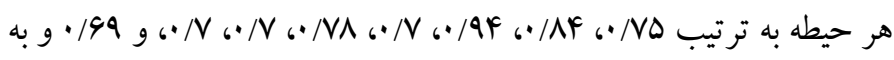

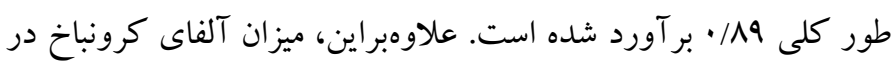

${ }^{1}$. career success questionnaire
${ }^{2}$. career anchors questionnaire 
جدول ا. ميانغين، انحراف استاندارد و همبستگى درونى ابعاد لنغر كاههاى شغلى وكلا و حقوقدانان

\begin{tabular}{|c|c|c|c|c|c|c|c|c|c|c|c|c|}
\hline 1. & 9 & $\wedge$ & $\checkmark$ & 4 & $\Delta$ & f & $r$ & r & 1 & $\begin{array}{l}M \\
\text { SD }\end{array}$ & متغيرها & \\
\hline & & & & & & & & & - & $\begin{array}{l}\text { Yr/Dr } \\
r / F r\end{array}$ & شايستخى فنى - كاركردى & 1 \\
\hline & & & & & & & & - & $\cdot / \Upsilon \Lambda^{* *}$ & $\begin{array}{l}\text { IN/DY } \\
r / 9\end{array}$ & مديريت عمومى & $r$ \\
\hline & & & & & & & - & $\cdot / Y \Delta^{* *}$ &.$/ T$ & $\begin{array}{l}\text { IQ/FY } \\
r / F F\end{array}$ & امنيت شغلى & $r$ \\
\hline & & & & & & - &.$/ 11$ & $\cdot / 4 T^{* *}$ & $\cdot / \notin r^{* * *}$ & $\begin{array}{l}r \cdot / 94 \\
r / 99\end{array}$ & خلاقيت كار آفرينانه & F \\
\hline & & & & & - & $\cdot / r v^{* *}$ & $-\cdot / 10$ & $\cdot / Y r^{* *}$ & $\cdot / I^{* *}$ & $\begin{array}{l}r \cdot / N Q \\
r / A\end{array}$ & استقلال & $\Delta$ \\
\hline & & & & - & $\cdot / r \Lambda^{* *}$ & $\cdot / \mu \varphi^{* *}$ &.$/ 19^{* *}$ & $\cdot / r q^{* *}$ & $\cdot|\Delta|^{* *}$ & $\begin{array}{l}r y / F q \\
r / .9\end{array}$ & خدمت و فداكارى & 9 \\
\hline & & & - & $\cdot / \Delta \mathrm{V}^{* *}$ & $\cdot / T V^{* *}$ & $\cdot / q^{* *}$ & (1/ & $\cdot / 44^{* *}$ & $\cdot / \Upsilon \Lambda^{* *}$ & $\begin{array}{l}r \cdot / \Delta V \\
r / r \Delta I\end{array}$ & جالش محض & $v$ \\
\hline & & - & $\cdot / f^{* * *}$ & $\cdot / 49^{* *}$ & $\cdot / \mu q^{* *}$ & $\cdot / \mu r^{* *}$ & - & $\cdot / \mathrm{TV}^{* *}$ & $\cdot / \mu V^{* *}$ & $\begin{array}{l}r \mid / \mu \\
r / \cdot \Delta\end{array}$ & سبكك زندگى با محوريت تعادل & $\wedge$ \\
\hline & - & $\cdot / A F$ & $\cdot / r \Lambda^{* *}$ & $\cdot / r \Delta^{* *}$ & $\cdot / r^{* * *}$ & MF. & $\cdot / \cdot r$ & $\cdot / 10$ & $\cdot / \mu^{* *}$ & $\begin{array}{l}\mid F / \Delta V \\
\Delta / T V\end{array}$ & موفقيت شغلى عينى & 9 \\
\hline- & $.19 r^{* *}$ & $\cdot / r \Delta^{* *}$ & $\cdot / r r^{* * *}$ & $\cdot / \mu \varphi^{* *}$ & . & $\cdot / \mathrm{TV}^{* *}$ & $\cdot / \cdot r$ & ( & $\cdot / r v^{* *}$ & $\begin{array}{l}r Y / M Y \\
\Delta / A F\end{array}$ & موفقيت شغلى فاعلى & 1. \\
\hline
\end{tabular}

$* * \mathrm{p}<\cdot / \cdots 1$

مقدار تورم واريانس از Y بيشتر باشد، ميزان همخطى بيشتر است و نبايد از

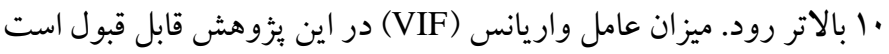

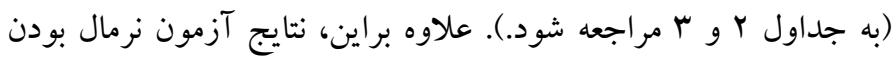
كولمو گروف - اسميرنوف در مورد متغير هاى موفقيت مسير شغلى عينى (·)

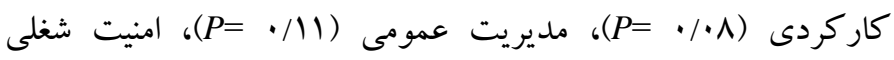

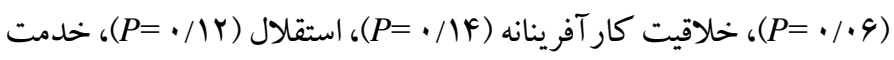
و فداكارى (19) محوريت تعادل كار - خانو اده (4.9=•
همانگگونه كه در جدول ا مشاهده مىشود، بين شايستخى فنى - كار كردى،

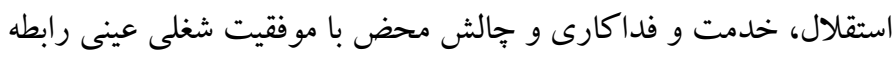

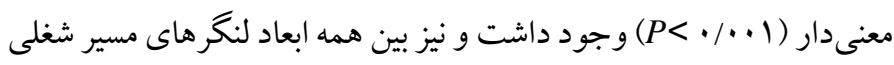
به جز مديريت عمومى و امنيت شغلى با موفقيت شغلى فاعلى رابطه معنى دار

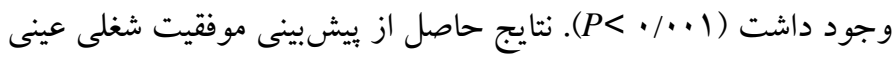

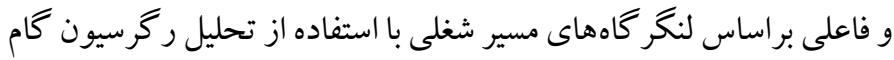

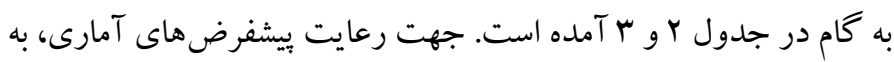
بررسى هم خطى جند گانه متغيرها با آزمون ضريب تحمل (Tolerance)،

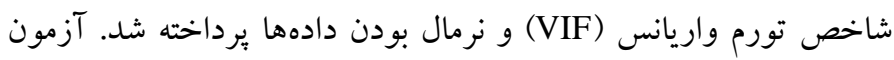

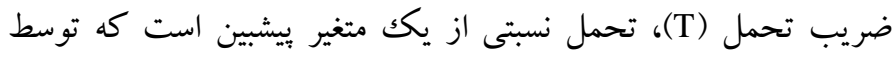

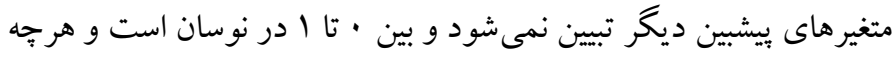

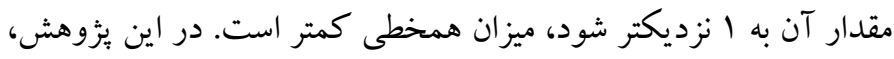
ضرايب تحمل زير ا قرار دارد (جداول r و r). همجنين، عامل تورم واريانس (VIF)، از تقسيم عدد ا بر ضريب تحمل به دست مى آيد. هرجه دردي 
جدول r. ييشينى موفقيت شغلى عينى براساس لنتر هاى مسيرشغلى

\begin{tabular}{|c|c|c|c|c|c|c|c|c|c|}
\hline Tolerance & VIF & $\begin{array}{c}\mathrm{R}\left(\mathrm{R}^{2}\right) \\
\mathrm{F}(\mathrm{p})\end{array}$ & $\mathrm{R} 2 \Delta$ & $P$ & $\mathrm{t}$ & $\beta$ & B & ابعاد لنخرهاى مسير شغلى & مراحل \\
\hline$\cdots / 1$ & $\cdots / 1$ & $\begin{array}{c}(11 / \cdot) \mu / \cdot \\
(\mathrm{p}<\cdot / \cdot 1) \mu r / 19\end{array}$ &.$/ 11$ & $\cdot / \cdots 1$ & $F / r q$ & תז/. & $\cdot / V F$ & شايستگى فنى - كاركردى & 1 \\
\hline $\begin{array}{l}. / 9 Y \\
. / 9 Y\end{array}$ & $\begin{array}{l}1 / \cdot 1 \\
1 / \cdot 1\end{array}$ & $\begin{array}{c}(1 \Delta / \cdot) r q / \cdot \\
(p<\cdot / \cdot \cdot) \text { gr r r }\end{array}$ & $\cdot / \cdot 4$ & $\begin{array}{l}\cdot \cdots 1 \\
\cdot / \cdots \wedge\end{array}$ & $\begin{array}{l}r / \Delta F \\
r / 94\end{array}$ & $\begin{array}{l}\cdot / r V \\
\cdot / r\end{array}$ & $\begin{array}{l}\cdot 191 \\
\cdot / 41\end{array}$ & شايستگى فنى - كاركردى & r \\
\hline
\end{tabular}

كار كردى و جالش محض با يكديخر ها درصد واريانس موفقيت شغلى

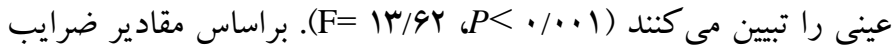
استاندارد بتاهاى جدول ميتوان بيان كرد كه شايستكى فنى - كار كردى

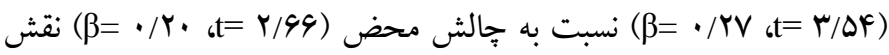
مهمترى در بيش بينى موفقيت شغلى عينى در و كلاو حقوقدانان داشت.
نتايج جدول r نشان مىدهد كه براساس R2A از ميان لنكرهاى مسير

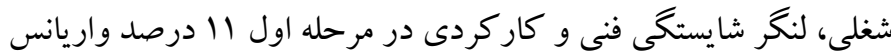

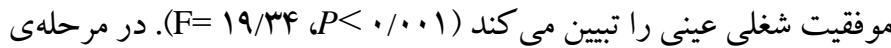

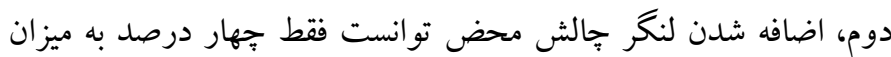

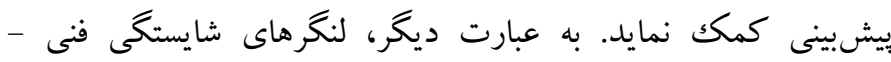

\begin{tabular}{|c|c|c|c|c|c|c|c|c|c|}
\hline Tolerance & VIF & $\begin{array}{c}\mathrm{R}\left(\mathrm{R}^{2}\right) \\
\mathrm{F}(\mathrm{p})\end{array}$ & $\mathrm{R} 2 \Delta$ & $P$ & $\mathrm{t}$ & $\beta$ & B & ابعاد لنخرهاى مسير شغلى & مر احل \\
\hline$\cdots / 1$ & $\cdots / 1$ & $\begin{array}{c}(\mid \mathrm{F} / \cdot) \mathrm{rV} / \cdot \\
(\mathrm{p}<\cdot / \cdot \cdot) \mathrm{V} / \mathrm{YF}\end{array}$ &.$/ 1 F$ & $\cdot \cdots 1$ & $F / 9 V$ & $\cdot \pi V$ &.$/ 91$ & شايستكى فنى - كار كردى & 1 \\
\hline $\begin{array}{l}. / 9 \\
. / 9\end{array}$ & $\begin{array}{l}1 / 1 \\
1 / 1\end{array}$ & $\begin{array}{c}(\mid \mathrm{N} / \cdot) \mathrm{Fr} / \cdot \\
(\mathrm{p}<\cdot / \cdot \cdot 1) \cdot 9 / 1 \mathrm{~V}\end{array}$ & $\cdot / \cdot f$ & $\begin{array}{l}\cdot 1 \cdots 1 \\
\cdot 1 \cdots \infty\end{array}$ & $\begin{array}{l}r / 9 F \\
\text { r/AG }\end{array}$ & $\cdot / r$ & $\begin{array}{l}\cdot / V F \\
\cdot / F \Delta\end{array}$ & شايستخى فنى - كاركردى & $r$ \\
\hline $\begin{array}{l}\cdot / \mathrm{MA} \\
\cdot / \mathrm{NI}\end{array}$ & $\begin{array}{l}1 / 14 \\
1 / 4 V\end{array}$ & $\begin{array}{c}(r \cdot / \cdot) \mathrm{r \Delta} / \cdot \\
(\mathrm{p}<\cdot / \cdot \cdot) q r / \mathrm{l} r\end{array}$ & $\cdot / \cdot r$ & $\begin{array}{l}\cdot / \cdot 1 \\
\cdot / \cdot 1 \\
\cdot / \cdot F\end{array}$ & $\begin{array}{l}r / \Delta \Lambda \\
r / \Delta F \\
r / \cdots\end{array}$ & $\begin{array}{l}\cdot / r Y \\
\cdot / 19 \\
\cdot / 1 Y\end{array}$ & $\begin{array}{l}\cdot / \Delta F \\
\cdot / F \cdot \\
\cdot / M\end{array}$ & شايستخى فنى - كاركردى & $r$ \\
\hline
\end{tabular}

نقش مهمترى در ييشينى موفقيت شغلى فاعلى در ( $\beta$ مر وكلا و حقوقدانان داشت.

\section{بحث و نتيجه كيرى}

هدف از يُزوهش حاضر، ييشبينى موفقيت شغلى عينى و فاعلى وكلا و حقوقدانان براساس لنكرهاى مسير شغلى آنها بود. يافتهها نشان داد كه از

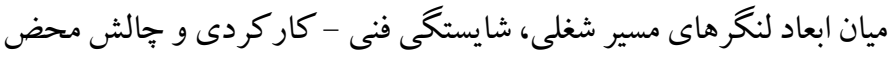
به ترتيب در بيشبينى موفقيت شغلى عينى و شايستكى فنى - كار كردى، استقلال و خدمت و فداكارى در ييشينى موفقيت شغلى فاعلى نقش

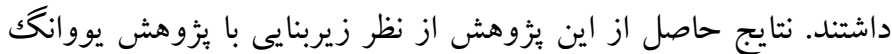

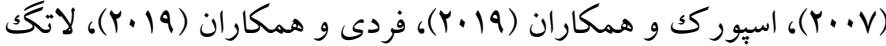

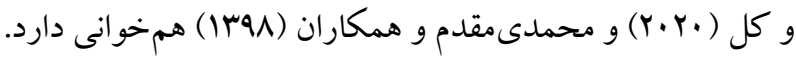

نتايج جدول r نشان مىدهد كه براساس R2D از ميان لنغرهاى مسير شغلى،

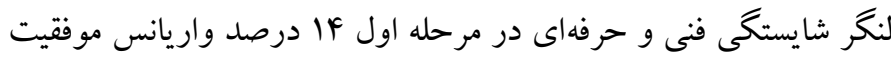

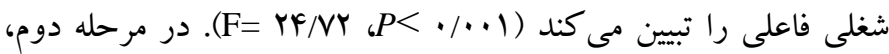
اضافه شدن لنكر استقلال توانست فقط جهاردرصد ميزان بيشينى افزايش دهد و در مرحله سوم، اضافه شدن لنكر خدمت و فداكارى به معادله، Y درصد به قدرت بيش بينى كمكك نمود. به عبارت ديخر، لنكر هاى

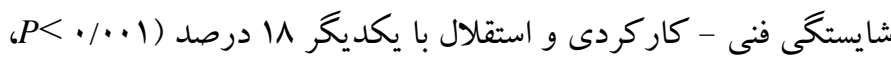

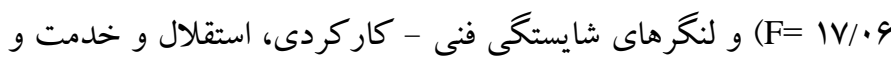

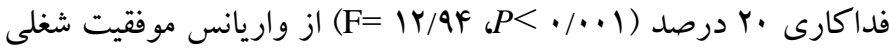
فاعلى را تبين مى كنند. همجِنين، براساس مقادير ضرايب استاندارد بتاهاى

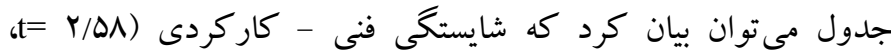
نا 
شغل و كالت با حالش همراه است. يك و كيل و حقوقدان، شرايط، ماهيت و ابعاد اجتماعى شغل خود را دركك نموده و از مسائل و مشكلات آن آكاهست. وى به دنبال اهداف آرمانى، علايق، اعتقادات و نيازهاى خود

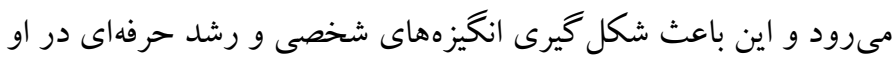

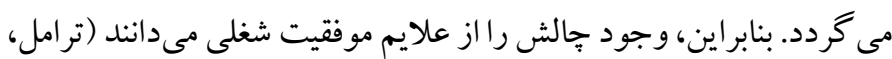

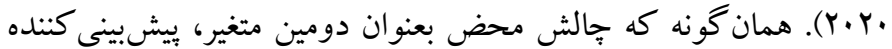

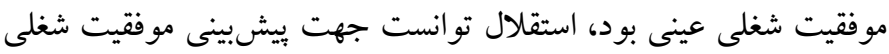

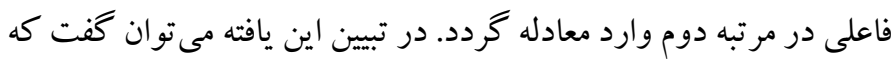

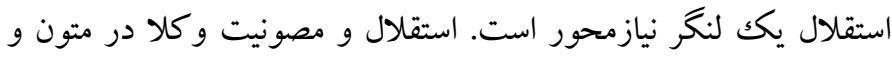
اسنادهاى حقوقى ذكر شده و از اصول اساسى و مورد نياز شغل وكالت

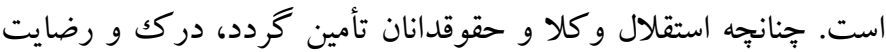
بيشترى نسبت به رعايت اصول اخلاقى، بيشرفت در كارشان، رشد و ترقى و رسيدن به اهداف شغلى خود و نيز حس خوب انجام فعاليتهاى شغلى را بيدا خواهند كرد (جو و كالوارد، ·ץ·ץ). احساس رضايت درونى، همان موفقيت شغلى ذهنى است. بعد از شايستخى فنى - كار كردى و استقلال، خدمت و فداكارى به عنوان سومين متغير، جهت بيشبينى موفقيت شغلى ذهنى در كنار دو متغير ديخر قرار گرفت. در لنخر خدمت و فداكارى،

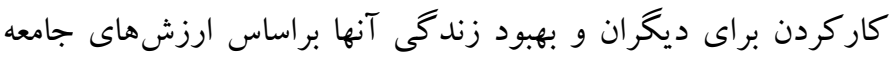

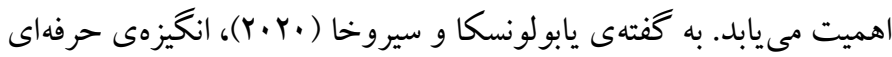
و يوياى و كلا و حقوقدانان، براساس مجموعهاى يبيجيده از علايق، نيازها، ارزشها، ميل به عدالت، عشق به حقيقت، وطندوستى و آرمانخواهى شكل مى گيرد. انخيزهاى كه بسيار تحت تأثير عوامل ذهنى قرار دارد. لذا،

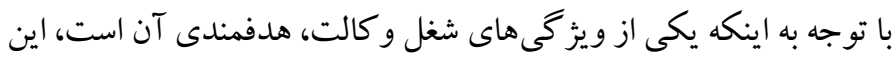
مى تواند در تمايل به خدمت، برقرارى عدالت اجتماعى، حمايت از حقوق

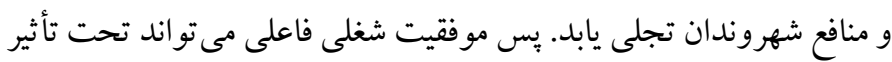
ميزان تحقق متغير خدمت و فداكارى در و كلا قرار گيرد. بنابراين مىتوان نتيجه گرفت كه در بيشبينى موفقيت شغلى و كلاو حقوقدانان هر سه لنكر

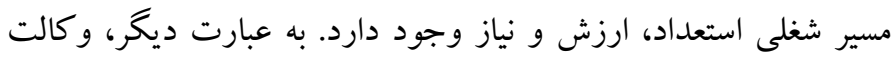
شغلى جندبعدى است و انجام فعاليتهاى شغلى آن مى تواند استعداد و ارزشهاى فرد را شكوفا سازد و نيازهاى او را برطرف نمايد. از جمله محدوديت هاى اين يثزوهش انجام آن در شهر اصفهان و نمونهاى از وكلا و حقوقدانان با سابقه يكك تا جهار سال و مدرك دكترى بود. در پايان،
بعل شايستخى فنى و كار كردى از لنخرهاى مسير شغلى بعنوان اولين متغير توانست هر دو نوع موفقيت شغلى عينى و فاعلى را بيشينى نمايد.

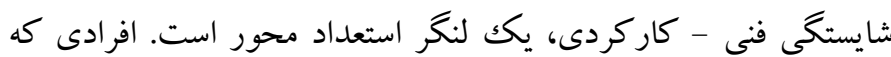
داراى لنكر مسير شغلى شايستخى فنى - كاركردى هستند، به دنبال

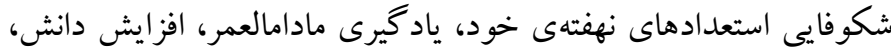
معلومات و مهارت تخصصى خود هستند. زيرا ماندكارى و بقاى آنها در دنياى بر از تحول و تغيير دنياى امروزى وابسته به افزايش دانش حقوقى و مهارت حرفهاى آنها در سطح مطلوب است (كوروتز و همكاران، •Y.Y.Y). همجنين، هرجه ميزان دانش، سابقه و مهارت وكلا افزايش يابد، ميزان ارجاع يروندههاى تخصصى و يرجالش به آنها بالاتر رفته و بدنيال آن

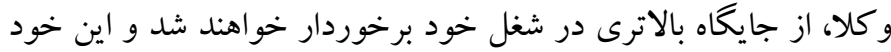

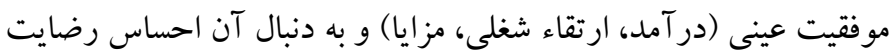

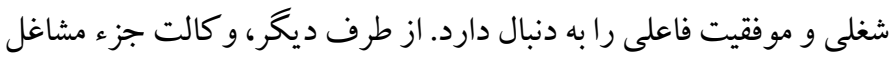

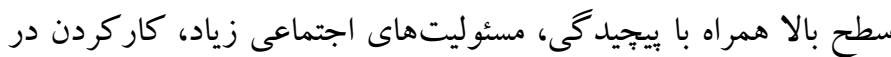
موقعيت هاى استرسزا و يرجّالش (يابولونسكا و سيروخا، ·r·r) مىباشد. و كلا و حقوقدانانى كه اين شغل را انتخاب كردند، داراى اهداف شغلى سطح بالا و در فعاليتهاى روزمره به دنبال ابراز شايستخىهاى فنى و كاركردى خود هستند. زيرا مىدانند دانش تخصصى و مهارت مى تواند

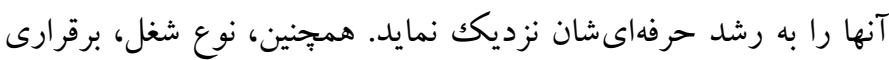
رتباط، تعهدى كه فرد به شغل دارد، حمايتهايى كه در شغل دريافت ميكند و انجام فعاليتهاى مربوط به آن مىتواند به فرد لذت دهد و در او احساس شايستخى ايجاد نمايد (ايبراموا، ·r.r).

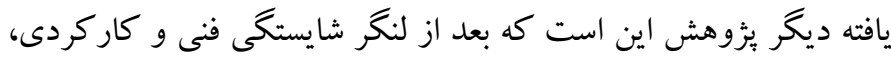
جالش محض هم توانست وارد معادله شود و موفقيت شغلى عينى را بيش بينى نمايد. در تبيين اين يافته مىتوان كفت كه در موفقيت شغلى براى و كلا علاوه بر وجود دانش تخصصى و شايستخى فنى - كار كردى، دست و ينجه

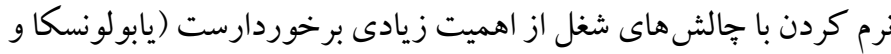

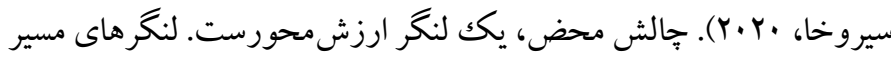
شغلى ارزشمحور با هويت شغلى و سازمانى رابطه دارند. جِنانجه افراد بتواند نيازهاى شغلى يا سازمانى خود را از طريق ارزشهايشان برآورده سازند (براون و لنت، ه ·r)، از طرف سازمان يا شغل خود تشويق مىشوند. تشويقى كه مى تواند جنبه هاى مادى هم داشته باشد. به عبارت ديخر، ماهيت 


\section{ملاحضات اخلاقى}

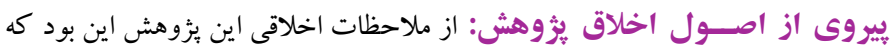

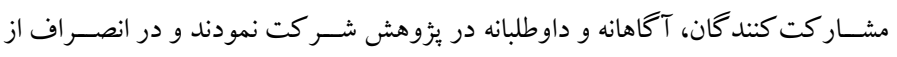

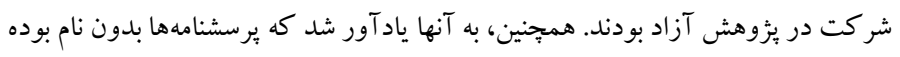

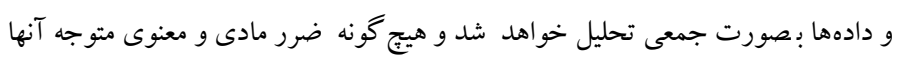
نخواهد شد. حامى مالى: اين يُوهش، بدون دريافت كمكك مالى انجام شده است.

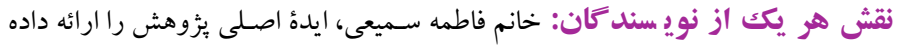

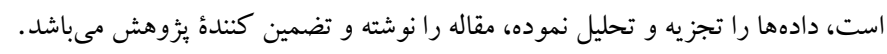
تضاد منافع: اين يُزوهش، داراى تضاد منافع نمىباشد. تشكر و قدردانى: نويسنده از كلئ وكلاو حقوقدانان كه در انجام اين يُوهشي، يارى رساندند، تشكر و قدردانى مىنمايد.
براساس يافتهاى يُزوهش، بيشنهاد مىشود سيستم قضايى كشور جهت احساس موفقيت شغلى و كلاو حقوقدانان، به لنخر كاههاى مسير شغلى آنها

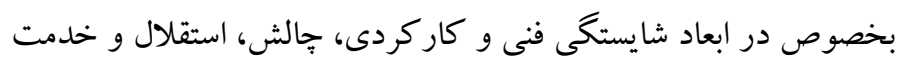
و فداكارى توجه كنند و شرايط كارى آنها را به شكلى فراهم نمايند كه ونه

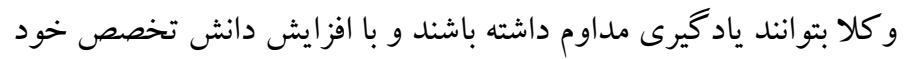

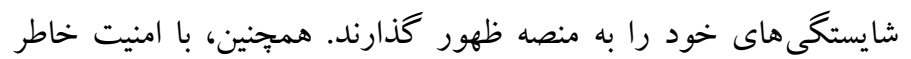

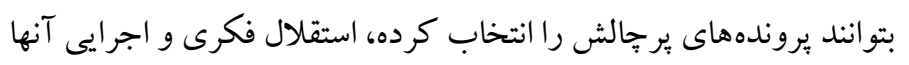
در روند بررسى يروندههاى قضايى حفظ گردد. علاوهبراين، نقش و كلا و

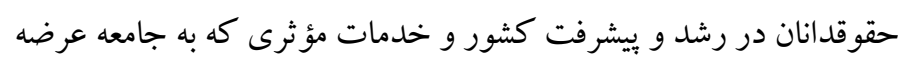
مى كنند، براى مردم روشن گردد. 


\section{References}

Brown, S. D., \& Lent, R. W. (2005). Career development and counseling. Putting theory and research to work. Canada: John Wiley \& Sons. [Link]

Chow, D. Y. L., \& Calvard, T. (2021). Constrained morality in the professional work of corporate lawyers. Journal of Business Ethics, 170(1), 213228. [Link]

Demchenko, D. I. (2019). Motivation in the prosess of training future lawyers foreign language. VIRTUS, 30, 83-85. [Link]

Frady, K. K., High, K., Hughes, C., \& Kosanovich, M. (2019, 16-19 October). Using career orientations to map professional formation in engineering technology. In 2019 IEEE Frontiers in Education Conference (FIE) (pp. 1-5). IEEE. [Link]

Ibragimova, S. (2020). The development of communicative competence in the future lawyers. European Journal of Research and Reflection in Educational Sciences, 8(3). 48-50. [Link]

Igbaria, M., Kassicieh, S. K., \& Silver, M. (1999). Career orientations and career success among research and development, and engineering professionals. Journal of Engineering and Technology Management, 16(1), 29-54. [Link]

Koruts, U. Z., Petkov, V. P., Nazymko, E. S., Denysova, T. A., \& Oliinyk, U. M. (2020). Formation of lifelong learning competences in the process of professional training of future lawyers. International Journal of Learning, Teaching and Educational Research, 19(4), 130-152. [Link]

Kulko, V., \& Timchenko-Mikhailidi, N. (2019). Research of career orientations of future philologists in higher educational establishment. Міжнародний науковий журнал Науковий огляд, 4(57), 138144. [Link]

Lambert, S. A., Herbert, I. P., \& Rothwell, A. T. (2020). Rethinking the career anchors inventory framework with insights from a finance transformation field study. The British Accounting Review, 52(2), 1-47. [Link]

Lang, J. W., \& Kell, H. J. (2020). General mental ability and specific abilities: Their relative importance for extrinsic career success. Journal of Applied Psychology, 105(9), 1047-1061. [Link]

Legal Gustice Center (2008). Careers in public interest law. Retrieved from: http://www.coachingforchange.com/pub28.html. [Link]
Martínez-León, I. M., Olmedo-Cifuentes, I., RamónLlorens, C. (2018). Work, personal and cultural factors in engineers' management of their career satisfaction. Journal of Engineering and Technology Management, 47, 22-36. [Link]

Mirzaeian, A., \& Mahdad, Ali. (2017). Predicting job effort and organizational citizenship behaviors through job motivation dimensions. Journal of Psychological Achievements, 24 (1), 111-126. (Persian). [Link]

Mohammadi Moghadam, Y., Dehnad, M., Delavar, A., \& Alipour Darvishi, Z. (2019). Develop strategies for anchoring the career path of employees. Strategic Management Studies of National Defense, 3(10), 418-449. (Persian). [Link]

Rezvanian, F., \& Samiee, F. (2016). Objective \& subjective career success: Role of career aspirations, personality and spirituality. Biannual Journal of Applied Counseling, 6(1), 23-36. (Persian). [Link]

Samiee, F., Sadeghian, A., \& Abedi, M. (2014). Manager's aspirations and success. Journal of Research in Human Resources Management, 6(1), 53-77. (Persian). [Link]

Schein, E. H. (1985). Career anchors: Discovering your real values. San Diego: CA, University Associates. [Link]

Schein, E. H. (1996). Career anchors revisited: Implications for career development in the 21st century. Academy of Management Executive, 10(4), 80-89. [Link]

Schworm, S. K., Cadin, L., Carbone, V., Festing, M., Leon, E., Muratbekova-Touron, M. (2017). The impact of international business education on career success-Evidence from Europe. European Management Journal, 35, 493-504. [Link]

Semeijn, J. H., Van der Heijden, B. I. J. M., \& De Beuckelaer, A. (2020). Personality traits and types in relation to career success: An empirical comparison using the big five. Applied Psychology, 69(2), 538-556. [Link]

Smale, A., Bagdadli, S., Cotton, R., Dello Russo, S., Dickmann, M., Dysvik, A., Martina Gianecchini, M., Kaše, R., Mila Lazarova, M., \& Rozo, P. (2019). Proactive career behaviors and subjective career success: The moderating role of national culture. Journal of Organizational Behavior, 40(1), 105122. [Link]

Snyder, P. (2015). Super women lawyers: A study of character strengths. Arizona Summit Law Review, 8(3), 261-316. [Link] 
Spurk, D., Hirschi, A., \& Dries, N. (2019). Antecedents and outcomes of objective versus subjective career success: Competing perspectives and future directions. Journal of Management, 45(1), 35-69. [Link]

Taylor, J., \& Joshi, K. D. (2019). Joining the crowd: The career anchors of information technology workers participating in crowdsourcing. Information Systems Journal, 29(3), 641-673. [Link]

Trammell, R. S. (2020). What do practicing lawyers need to know about technology? Wiley Interdisciplinary Reviews: Forensic Science, 2(4), 1-9. [Link]

Yablonska, T., \& Sirokha, L. (2020). The peculiarities of career crises of lawyers: Psychological and social aspects. Roczniki Teologiczne, 67(1), 129-144. [Link]

Yazdani, A. H., Najafi, M., AminBaidokhti, A. A., Mohammadyfar, M. A., \& Rahimian Boogar, I. (2021). The effectiveness of organizational intelligence training program on job satisfaction and job motivation in employees. Psychological Science, 20(99), 379-390. (Persian). [Link]

YuWong, A.L. (2007). Making career choice: A study of Chinese managements. Journal Human Relations, 60(8), 1211-1233. [Link] 